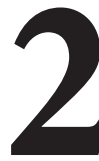

\title{
COMPETENCIAS SOCIALES E INMIGRACIÓN DESDE UNA PERSPECTIVA INTERCULTURAL ${ }^{1}$
}

\author{
(SOCIAL COMPETENCES AND IMMIGRATION FROM AN INTERCULTURAL \\ PERSPECTIVE)
}

José Antonio Ibáñez-Martín, Juan Luis Fuentes

y José María Barrio Maestre

Universidad Complutense de Madrid

\section{RESUMEN}

La aceptación generalizada del interculturalismo como el modelo más apropiado para afrontar la diversidad cultural ha dado paso a la discusión sobre los medios más adecuados para llevarlo a la práctica. Esta responsabilidad recae en gran medida en la pedagogía, quien debe realizar una propuesta educativa que vaya más allá de la simple búsqueda de la eficacia en la transmisión de los elementos culturales mayoritarios, y se plantee primeramente el descubrimiento de los valores que, por ser compartidos por todos, puedan ser considerados como transculturales, y que por ello convenga cultivarlos de modo especial para fomentar la cohesión social. En este artículo, abordamos esta cuestión acudiendo al análisis de los elementos de la competencia social, tal como la define la Unión Europea, y para ello hemos realizado un estudio con más de 1600 alumnos de educación secundaria obligatoria en la ciudad de Madrid. Al no encontrar diferencias significativas en el desarrollo de los diversos elementos de la competencia social entre inmigrantes y españoles, y descubrir distintas percepciones de estos elementos entre ambos grupos de estudiantes, podemos concluir su transculturalidad y la importancia de su cultivo.

\section{ABSTRACT}

Nowadays interculturalism has been widely accepted as the most appropriate model to address cultural diversity, and it has generated various dis- 
cussions on the ways in which it can be applied for. The responsibility of applying this approach falls considerably on pedagogy. Educators should provide a proposal that goes beyond the mere assimilation of the cultural majority and reveals certain values that could be shared by all, and may be characterized as cross-cultural. In this article we will focus on this issue which is under discussion. After having conducted a research where more than 1600 secondary students took part in , the findings revealed that there were no significant differences in the development of the different components of social competence defined by European Union, between migrants and Spanish pupils. However, there have been found differences in the perception of these fundamental elements between the two groups of students, therefore we can conclude that social competence is transcultural and an important element in intercultural education.

\section{PLANTEAMiENTO DEL PROBLEMA}

Pocos temas han sido objeto de una discusión social más compleja que el modo de responder al progresivo pluralismo social que, de forma cada vez más amplia, ha ido consolidándose en numerosos países, en la medida en que la desigualdad mundial en el reparto de la riqueza y las guerras han motivado un aumento extraordinario de los movimientos migratorios.

Esta discusión no tenía lugar cuando se consideraba que los inmigrantes simplemente habían de asimilarse a la cultura mayoritaria del país, por lo que la única preocupación educativa consistía en encontrar los procedimientos pedagógicos más eficaces para alcanzar la asimilación proyectada. Pero el último medio siglo ha dejado claro que esa no era una política social adecuada, porque planteaba problemas no pequeños tanto en los propios nacionales como en los inmigrantes. En efecto, el pluralismo no siempre dependía de la llegada de extranjeros sino que muchos países tenían una considerable variedad interior, que ante la mitología del asimilacionismo tendía a eliminarse, para conseguir una homogenización a favor de los elementos culturales del grupo dominante en la nación (Olveira Olveira y Santos Rego, 2000).

Naturalmente, los problemas terminaban siendo mayores para los inmigrantes, pues ese horizonte asimilacionista tendía a promover el desprecio hacia su cultura y, en última instancia, hacia sus personas. Por ello, muy frecuentemente terminaban viviendo en nuevos ghettos, con escasas dotaciones de servicios públicos y de equipamientos culturales, y con una participación en la vida cívica limitada a trabajar en las actividades que los nacionales rechazaban (Lora-Tamayo, 2009; Suárez Orozco y Suárez Orozco, 2003), de forma que, de hecho, se les incitaba a volver a su país de origen en cuanto les fuera posible. 
Poco a poco se fue haciendo patente que esa política no era compatible con las exigencias de la dignidad humana y por ello, en el último cuarto del pasado siglo, se produjo una fuerte reacción, que buscaba otro modo de afrontar las nuevas realidades sociales (Parekh, 2006). De esta forma surgió el multiculturalismo, que, como es sabido, ha tenido muy diversas versiones en estos años, que no es cuestión de desarrollar en este contexto. Ahora bien, sí es preciso señalar que la evolución de las distintas perspectivas de este enfoque, ha ido configurando su concepto hacia una posición que quizá magnifica al grupo, incluso situándole por encima del individuo, y que tiende a defender un respeto incondicionado a toda práctica vigente en cualquier grupo cultural, evitando posiciones críticas que pudieran herir a alguno de sus miembros (Sáez Alonso, 2006). En este horizonte, la única preocupación educativa habría de ser la de rechazar cualquier violencia, promover los principios democráticos de convivencia y facilitar un diálogo en el que todos los individuos expondrían sus posturas sin que a nadie le estuviera permitido evaluar negativamente ninguna posición del otro, pues con ello, se dice, se comprometería su dignidad.

Ahora bien, esta forma de enfrentarse con el pluralismo social igualmente se ha manifestado como una fuente de problemas tanto para los nacionales como para los inmigrantes. Sin lugar a dudas, en no pocos lugares se ha dado una deformación del legítimo amor a las propias raíces, que se ha transformado en un nacionalismo exacerbado, amasado de tierra y sangre, que no tolera la convivencia con quien tiene raíces distintas. La cuestión de la identidad, "problema esencial de la filosofía desde el "conócete a ti mismo» de Sócrates hasta Freud» (Maalouf, 2000, 17), ha recobrado un fuerte protagonismo en los últimos años motivado por la creciente diversidad de nuestras sociedades. Estamos siendo testigos de una continuada presencia del cuidado de la identidad nacional en el discurso político de los estados europeos ${ }^{2}$. El rechazo de las políticas asimilacionistas y el esperado reconocimiento público de la multiculturalidad de muchos países occidentales en los años 90 (May, 2009), parecía augurar una apertura de los planteamientos identitarios, como lucidamente han propuesto Maalouf (o.c.) y Sen (2006). Sin embargo, el deseo de una identidad nacional puede convertirse en elemento de exclusión, entre otras razones, si concebimos los valores universales como exclusivos de una determinada cultura (Sales, 2010); lo que sólo nos llevaría a posturas ante la diversidad más propias de épocas coloniales, donde la supuesta superioridad moral de occidente pretendía legitimizar el sometimiento de los colonizados. Pero ese error no puede cambiarse por aquel que implica mantener que la identidad cultural de una nación no tiene derecho alguno a ser especialmente cuidada (Hansen, 2010; Ben-Porath, 2012; Parra, 2011). Más aún, la actitud etnocéntrica, que considera que toda la verdad del ser humano está en su propia cultura, es una falacia que no se corrige 
manteniendo que todas las culturas expresan igualmente las mejores realizaciones del ser humano (cfr. Boghossian, 2009). Un personaje de Némirovsky $(2009,65)$ señala que lo que había ido a buscar a Europa no era solo la riqueza sino «la dignidad, el desinterés, una educación exquisita, el orgullo que aniquila el mal haciéndole caso omiso». En efecto, una evaluación objetiva de la realidad muestra que no es cierto que toda práctica cultural tenga el mismo valor, ni que, por tanto, haya de ser respetada incondicionalmente [3]. Por el contrario, hay elementos culturales que expresan mejor que otros al ser humano y ello explica la atracción que tienen para quien los conoce. Sería desacertado abandonar toda tarea de discernimiento, pues con ello se impediría el descubrimiento de las aportaciones positivas de los demás, e incluso se promovería el enclaustramiento en prácticas culturales empequeñecedoras, cuando no lesivas de la dignidad del ser humano.

Estas ideas han movido al desarrollo de una nueva política que propone el modelo intercultural como el enfoque más beneficioso para nacionales e inmigrantes. Naturalmente no nos encontramos ante una propuesta que carezca de dificultades, como se aprecia cuando se trata de concretar las medidas prácticas para su desarrollo (Cfr. Banks, 2009). Y buena muestra de ello puede ser el White Paper elaborado por el Consejo de Europa (2008) sobre el diálogo intercultural, cuyo texto final sólo es capaz de aportar algunas líneas muy generales a la hora de determinar los modos de llevarla a la práctica.

Por ello, nos ha parecido necesario precisar los elementos que consideramos básicos en nuestra propuesta intercultural, orientadores del presente estudio que aspira a realizar una aportación sobre el modo de facilitar el pleno desarrollo de su personalidad a los inmigrantes y el modo de facilitársela igualmente a los nacionales que con ellos conviven. Concretamente proponemos siete puntos que entendemos especialmente relevantes:

1. La nueva sensibilidad hacia los derechos humanos exige en todos respetar sustancialmente la identidad cultural de los demás, respetar aquello que el otro ama. Obviamente esto excluye actitudes de hostilidad y desprecio, así como superación de distanciamientos soberbios, que todo lo más condescienden en acercarse al otro con un planteamiento, diríamos, entomológico.

2. Tal respeto no significa que haya de pensarse que toda cultura posee sus propios valores desde los que únicamente pueda ser juzgada, sin que quepa un enjuiciamiento objetivo del acierto de sus normas o prácticas. El interculturalismo exige dotar a las jóvenes generaciones de los dispositivos críticos precisos para analizar el acierto de cualquier propuesta cultural. $\mathrm{La}$ 
experiencia muestra que un camino eficaz en este sentido es promover el conocimiento y respeto de de los Derechos Humanos (Wulf, 2008). Hoy no son pocos «quienes propagan un relativismo cultural que deja de considerar a los derechos como universales, indivisibles, inalienables e inherentes a la persona, para hacerlos depender de la interpretación que de ellos proponga la cambiante mentalidad dominante o los intereses más pedestres de las naciones poderosas» (Ibáñez-Martín, 2009, 18). Pero la falta de oposición en su aprobación por las Naciones Unidas muestra que tales derechos expresan la transculturalidad de que es capaz la inteligencia humana, la cual exige una constante investigación actualizada de los fundamentos en los que tales derechos se basan, profundizando en las características propias de la condición humana.

3. Tal enjuiciamiento crítico de los elementos culturales sería inoperante si no va acompañado de la posibilidad libremente decidida de modificar la conducta habitual cuando se descubre que, de algún modo, lesiona la dignidad humana (Merry y de Ruyter, 2011). No hay educación real cuando sólo está presente el deseo de socializar en los criterios dominantes de la propia cultura. Asimismo, quienes muestran sus deseos de incorporarse a otro grupo cultural deben verse acogidos por él, evitándose actitudes de rechazo hacia quienes poseen orígenes distintos a los propios.

4. La decisión de modificar cualquier comportamiento que atente contra la dignidad humana no es en absoluto contraria al cuidado por custodiar los valores esenciales que dan unidad a la propia sociedad y que, muchas veces, son una mezcla de elementos sustantivos y adjetivos, endeudados a una historia que debe ser continuada, de no mediar graves razones. Este respeto a la identidad cultural de una comunidad no se basa en la creencia de que existan hipóstasis nacionales, sino en el reconocimiento de que el amor a las raíces es un elemento esencial para el sereno crecimiento de la mayoría de los individuos (Pérez Juste, 2008).

5. Los valores propios de cada cultura suelen estar mezclados con elementos secundarios, a los que algunos prestan una importancia desaforada. Todos deben ser enseñados a descubrir cuáles son los pilares constituyentes de su cultura y a distinguirlos de los accesorios, sabiendo conceder un peso distinto a unos y a otros (Barrio, 2007).

6. Los ciudadanos y los poderes públicos deben empeñarse en atender las necesidades de quienes provienen de culturas diversas. Concretamente: a) Es necesario desarrollar actitudes de empatía con los demás, haciendo un esfuerzo por ponernos en sus problemas y manifestando así nuestra solidaridad con los otros; b) deben concederse créditos especiales a las escuelas para la enseñanza de la lengua local a quienes no la tienen como lengua materna; 
c) a partir de un cierto número de personas se ha de proporcionar enseñanza en la propia lengua de los inmigrantes, al menos durante el periodo de aclimatación al nuevo entorno cultural.

7. Asimismo, el material educativo siempre ha de ser estudiado para evitar que promueva actitudes erróneas, como el sexismo. Pero una educación intercultural exigirá, además, un especial esfuerzo, dentro del respeto a la libertad de cátedra y a la libertad de opinión de los estudiantes, para cuidar que las interpretaciones de la historia, de la literatura, etc., objetivamente puedan ofender los sentimientos de grupos culturales diversos (Banks, 2009, 2006, 2003; Esteve, 2005). Este mismo cuidado habrá de tenerlo el profesor para saber decodificar los comportamientos de sus distintos alumnos (bajar la mirada no significa lo mismo en un niño anglosajón que en uno mejicano) y para evitar imponer prácticas de escasa relevancia o deportes contrarios a las normas culturales de algunos de sus alumnos.

Dentro de este marco de ideas se encuadra el presente estudio, que se concentra en el análisis de la competencia social descrita en del Parlamento Europeo y del Consejo de 18 de diciembre de 2006 (2006/962/CE). Concebida como una de las competencias clave para el aprendizaje permanente, está constituida no sólo por conocimientos conceptuales y procedimientos pedagógicos, sino también por elementos cuyo aprendizaje debe permitir al estudiante un saber convivir y un saber ser (García Amilburu y Ruiz Corbella, $2009,109)$. En definitiva, se trata de una competencia que expresa la capacidad para orientar la existencia en la sociedad plural en la que se vive, en orden a alcanzar así «la plena realización personal, la ciudadanía activa, la cohesión social y la empleabilidad en la sociedad del conocimiento» (Unión Europea, 2006, 14).

Como señalan los profesores Suárez Orozco (2003), los estudios sobre inmigración tradicionalmente se han venido centrando en cuestiones meramente políticas y económicas. Y aunque ciertamente cada vez son más frecuentes los trabajos que vinculan la pedagogía con la diversidad cultural ${ }^{4}$, resulta pertinente abordar la interculturalidad desde su dimensión de educación en valores (Touriñán, 2006; García López, 2003), en un momento en el que la política educativa internacional parece haberse instalado en un discurso monolingüe que se olvida de los fines y de la dimensión moral de la acción educativa (Harris, 2011).

\section{OBJETIVOS Y METODOLOGÍA}

Una vez planteados los presupuestos teóricos que han motivado nuestra investigación, pasemos ahora a exponer los objetivos y la metodología 
utilizada, para continuar después con el análisis de resultados, donde pondremos en evidencia los hallazgos más significativos y discutiremos su relevancia educativa.

El objetivo fundamental de nuestra investigación consiste en analizar si efectivamente los principales elementos de la competencia social tal y como queda definida por, pueden considerarse transculturales ${ }^{5}$, es decir, si son aceptados como propios por aquellos que no pertenecen al grupo cultural mayoritario, a pesar de que inicialmente se conciban de manera diferente. Para ello, el procedimiento que seguimos constó de dos fases. Elaboramos un cuestionario en el que se incluían, por un lado, 49 ítems donde se operativizaban los principales elementos de la competencia social ${ }^{6}$, de tal forma que se pudiera comprobar si existen diferencias en el desarrollo de dicha competencia dependiendo de si se tiene origen español o inmigrante. Por otro lado, incluimos también cinco preguntas en las que se pedía a los estudiantes que evaluaran el grado de coincidencia de los principales valores que agrupan los elementos de la competencia social, entre su grupo de origen y el grupo mayoritario ${ }^{7}$.

Una reflexión a varias voces sobre la definición de la competencia social proporcionada por citada, nos llevó a concluir que en ella pueden encontrarse catorce elementos que cabe agrupar en torno a seis valores ${ }^{8}$, tal y como se observa en el esquema siguiente:

Valores que agrupan los elementos de la competencia social

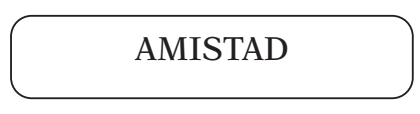

COMPRENSIÓN

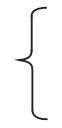

Relaciones de amistad

Comprensión de códigos de conducta y usos generalmente aceptados

Expresión y comprensión de puntos de vista diferentes

Empatía 


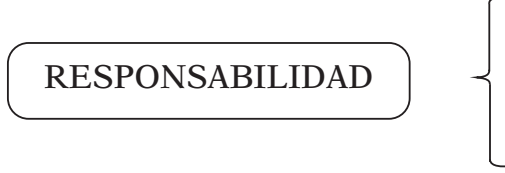

1

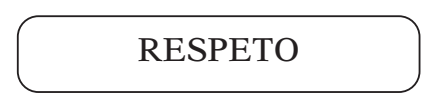

GENEROSIDAD

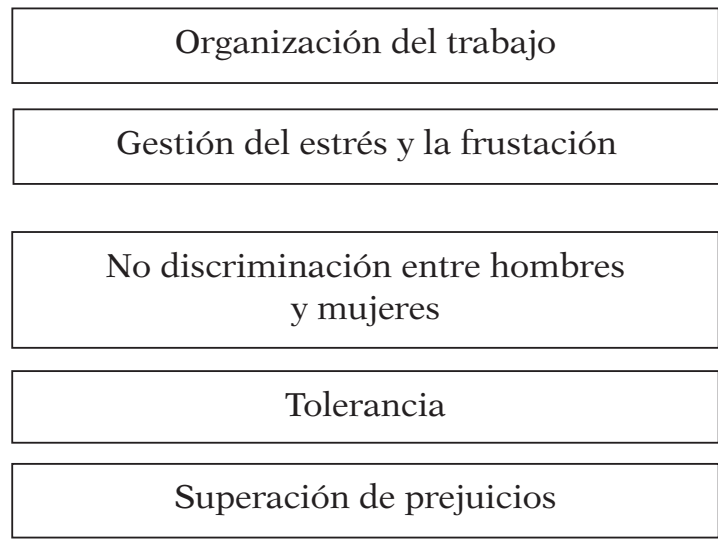

Respeto a los demás

Comunicación Constructiva

Actitud de colaboración

Negociación

Comunicación intercultural

Ante esta clasificación es preciso realizar dos apuntes. Hemos identificado el valor Amistad a pesar de que en la descripción de la competencia social no se alude explícitamente al mismo. Sin embargo, resulta difícil imaginarse una formación en tales competencias sin el establecimiento de vínculos interpersonales que vayan más allá del mero compañerismo. Así pues, algunos de los elementos que forman parte de la competencia social tales como el compromiso, la comunicación constructiva, la empatía, la colaboración o el respeto, parecen encontrarse entre los pilares que sustentan una relación de amistad. Además, es sabida la alta importancia que las amistades ocupan en la época adolescente, por lo que un trabajo sobre las relaciones sociales en jóvenes no puede dejar de lado un aspecto como éste.

Unido a esto, es necesario notar que no se ha incluido un elemento incorporado en la definición de la competencia social referido al conocimien- 
to de la identidad europea. Si bien no puede negarse su importancia creciente en el contexto actual (Soriano y Peñalva, 2011), la complejidad de su interpretación distorsionaría los resultados de este estudio.

Así las cosas, el cuestionario estaba conformado por los 54 ítems indicados que se intercalaban con otros 8 dirigidos a evaluar los valores descritos de la competencia social en el grupo mayoritario ${ }^{9}$. Previamente a esta parte central del cuestionario, se incluyeron una serie de preguntas encaminadas a registrar algunos datos personales que nos permitieran estudiar relaciones entre las diversas variables.

Hay que señalar que, debido a la interconexión de los valores y elementos descritos, algunos de los ítems se encuentran en varios grupos de los recogidos en el esquema anterior.

El sistema de respuesta de la parte principal del cuestionario consistía en una escala en la que los alumnos debían autoevaluar su comportamiento en función de la frecuencia con que realizaran las acciones que en los ítems se plantearan (1 - Nunca, 2 -Muy pocas veces, 3 - Algunas veces, 4 - La mayoría de las veces, 5 - Siempre). El cuestionario fue sometido inicialmente a un proceso de validación de contenido mediante un juicio de expertos a través del Método de Agregados Individuales (Corral, 2009), en el que participaron cinco profesores de diversos departamentos de de Educación de de Madrid, cuyas observaciones se tuvieron en cuenta para redactar la versión definitiva del mismo. Unido a esto, se analizó su fiabilidad obteniendo un Alfa de Cronbach de 0,81 con una serie de cuestionarios pasados en el primer centro educativo al que se acudió.

Para la selección de la muestra se utilizó un procedimiento estratificado en el que se trataron de seleccionar centros con porcentajes de alumnado inmigrante superiores a la media de la ciudad de Madrid. Asimismo, se tuvo en cuenta el criterio del tipo de centro (público-concertado) y su ubicación en los barrios y distritos de la capital más procedentes para la investigación.

Al centrarse nuestro interés en los aspectos culturales, convenimos en denominar «inmigrantes» a aquellos alumnos que tuvieran al menos uno de sus padres de origen diferente al español. De esta forma, incluimos bajo tal denominación también a aquellos considerados inmigrantes de segunda generación. Por ello, las denominaciones «españoles» o «inmigrantes» usadas en este artículo, se refieren exclusivamente al origen familiar de los estudiantes encuestados. 


\section{RESULTADOS OBTENIDOS}

Los cuestionarios fueron pasados durante el segundo trimestre de 2010. Obtuvimos una muestra de 1662 alumnos que acudían a 18 centros educativos (11 públicos; 7 concertados), situados en 11 distritos de los 21 que conforman la ciudad de Madrid. La media de población inmigrante en los barrios donde se ubican tales centros se sitúa en el 25,5\%. Esto supone casi 10 puntos porcentuales por encima de la media de la ciudad 16,2\% (Ayuntamiento de Madrid, 2010) y casi 7 puntos sobre la de los centros educativos, que en el curso 08/09 rondaba en el 18,6\% (Comunidad de Madrid, 2009). La distribución por sexos fue de 52,1\% Mujeres - 47,9\% Varones, mientras que la franja de edad se situaba entre los 13 y 18 años, siendo el intervalo 14-15 donde se encontraba la mayoría de los alumnos $(60,7 \%)$. Los cursos a los que se acudió fueron todos los de excepto el primero, a fin de evitar problemas de comprensión de las preguntas contenidas en el cuestionario, entre las cuales podrían encontrarse algunas que requieren cierto grado de madurez. La distribución obtenida es bastante homogénea $\left(2^{\circ}\right.$ : $\left.36,5 \% ; 3^{\circ}: 32,7 \% ; 4^{\circ}: 30,7 \%\right)$ observándose una comprensible disminución del número de estudiantes en los cursos superiores.

El 59,3\% de los alumnos encuestados señalaron que España es el origen cultural de sus dos padres ${ }^{10}$, mientras que el grupo de «inmigrantes» lo conformaron un $40,1 \%$ de la muestra $-0,6 \% \mathrm{~ns} / \mathrm{nc}-$. En este grupo pueden diferenciarse a su vez dos subgrupos, «inmigrantes de $1^{\text {a }}$ generación» e «inmigrantes de $2^{\text {a }}$ generación» dependiendo de si su lugar de nacimiento es España. El porcentaje de unos y otros sobre la muestra total es de 32,7\% y $7,3 \%$ respectivamente.

\subsection{Aspectos centrales de la investigación}

Los resultados en los diferentes valores de la competencia social, tal como se recogen en la siguiente tabla, muestran que la puntuación más alta se obtiene en y la más baja corresponde a a los elementos - parte derecha de la tabla-, la «Expresión y comprensión de puntos de vista diferentes» alcanza el mayor resultado, frente a la «Gestión del estrés y la frustración» que obtiene el más bajo. Con respecto a los ítems —no incluidos en la tabla por razones de espacio-, cabe destacar los dos extremos: Creo que hombres y mujeres deben tener los mismos derechos $(4,72)$ como el que obtiene mayor media, mientras que Sólo estudio antes de los exámenes $(1,65)$ es el que menor puntuación presenta ${ }^{11}$. 


\begin{tabular}{|c|c|c|c|}
\hline Valores & $\overline{\mathrm{X}}$ & Elementos de la competencia social & $\overline{\mathrm{X}}$ \\
\hline AMISTAD & 3,60 & Relaciones de amistad & 3,60 \\
\hline \multirow{3}{*}{ COMPRENSIÓN } & \multirow{3}{*}{3,86} & $\begin{array}{l}\text { Comprensión de códigos de conducta y } \\
\text { usos generalmente aceptados }\end{array}$ & 3,93 \\
\hline & & $\begin{array}{c}\text { Expresión y comprensión de puntos de } \\
\text { vista diferentes }\end{array}$ & 4,08 \\
\hline & & Empatía & 3,57 \\
\hline \multirow{2}{*}{ RESPONSABILIDAD } & \multirow{2}{*}{2,79} & Organización del trabajo & 2,85 \\
\hline & & Gestión de estrés y frustración & 2,74 \\
\hline \multirow{4}{*}{ RESPETO } & \multirow{4}{*}{3,69} & No discriminación entre hombres y mujeres & 3,71 \\
\hline & & Tolerancia & 3,92 \\
\hline & & Superación de prejuicios & 3,68 \\
\hline & & Respeto a los demás & 3,47 \\
\hline \multirow{3}{*}{ GENEROSIDAD } & \multirow{3}{*}{3,30} & Comunicación constructiva & 3,06 \\
\hline & & Actitud de colaboración & 3,57 \\
\hline & & Negociación & 3,28 \\
\hline INTERCULTURALIDAD & 3,56 & Comunicación intercultural & 3,56 \\
\hline$\overline{\mathrm{X}}$ Total & 3,47 & $\overline{\mathrm{X}}$ Total & 3,50 \\
\hline
\end{tabular}

Tabla 1. Valores obtenidos en la valoración de los diferentes elementos de la competencia social

Como hemos indicado en el apartado anterior, para constatar la afirmación sobre la transculturalidad de los aspectos fundamentales de la competencia social es necesario analizar dos cuestiones. Por un lado, comprobar si existen diferencias significativas en el desarrollo operativo de dicha competencia entre alumnos pertenecientes al grupo de «españoles» y al de «inmigrantes». Y por otro, conocer si los estudiantes inmigrantes dicen comprender los aspectos principales de la competencia social de manera diferente a como los perciben en la cultura mayoritaria.

Comencemos por la primera. En el análisis estadístico mediante la prueba $\mathrm{T}$ de los ítems incluidos en los 6 valores descritos, obtenemos que no hay diferencias estadísticamente significativas en las respuestas de españo- 
les y de inmigrantes, en todos los valores excepto en la Amistad ( 0,01). Si bien es cierto que no todas las preguntas muestran este resultado, aunque sí la gran mayoría, los datos apuntan a una abrumadora igualdad en ambos grupos. Veamos esto con mayor detalle.

En el caso de las pruebas estadísticas indican diferencias significativas en los tres primeros ítems que muestran cómo el grupo de españoles presenta puntuaciones más altas que sus compañeros, lo que parece reflejar una mayor facilidad objetiva en éstos a la hora de estrechar amistades. Sin embargo, la diferencia de medias y el análisis de porcentajes muestra la poca relevancia de estas discrepancias. Asimismo y a la luz de las altas puntuaciones obtenidas por ambos grupos, parece innegable que la amistad constituye un aspecto muy valorado por todos los estudiantes independientemente de su procedencia.

\begin{tabular}{|c|c|c|c|c|c|c|c|c|c|c|}
\hline \multicolumn{11}{|c|}{ «Relaciones de amistad» } \\
\hline \multirow{2}{*}{ Ítem } & \multirow{2}{*}{$\overline{\mathrm{x}} \mathrm{t}$} & \multirow{2}{*}{ S } & \multirow{2}{*}{$\overline{\mathrm{X}} \operatorname{Esp}$} & \multirow{2}{*}{$\overline{\mathrm{X}} \operatorname{Inm}$} & \multirow{2}{*}{ Dif. $\overline{\mathrm{X}}$} & \multicolumn{5}{|c|}{$\% \operatorname{Esp} /$ Inm } \\
\hline & & & & & & 1 & 2 & 3 & 4 & 5 \\
\hline \multirow{2}{*}{2} & \multirow{2}{*}{3,49} & \multirow{2}{*}{1,044} & \multirow{2}{*}{3,63} & \multirow{2}{*}{3,30} & \multirow{2}{*}{,33 } & 3,0 & 12,4 & 24,6 & 38,6 & 21,4 \\
\hline & & & & & & 7,9 & 19 & 26,3 & 28,5 & 18,3 \\
\hline \multirow{2}{*}{4} & \multirow{2}{*}{4,12} & \multirow{2}{*}{,900 } & \multirow{2}{*}{4,26} & \multirow{2}{*}{3,89} & \multirow{2}{*}{,38 } & 1,1 & 3,1 & 14,9 & 30,2 & 50,7 \\
\hline & & & & & & 2,9 & 8,8 & 20,6 & 32,0 & 35,7 \\
\hline \multirow{2}{*}{7} & \multirow{2}{*}{4,17} & \multirow{2}{*}{,867 } & \multirow{2}{*}{4,27} & \multirow{2}{*}{4,02} & \multirow{2}{*}{25} & 1,2 & 2,7 & 12,3 & 35,2 & 48,6 \\
\hline & & & & & & 2,0 & 6,5 & 19,1 & 32,4 & 40,1 \\
\hline \multirow{2}{*}{14} & \multirow{2}{*}{2,15} & \multirow{2}{*}{1,149} & \multirow{2}{*}{2,12} & \multirow{2}{*}{2,19} & \multirow{2}{*}{,- 08} & 38,6 & 28,8 & 19,8 & 8,2 & 4,7 \\
\hline & & & & & & 40,6 & 22,2 & 20,2 & 10,8 & 6,1 \\
\hline \multirow{2}{*}{39} & \multirow{2}{*}{3,45} & \multirow{2}{*}{1,101} & \multirow{2}{*}{3,40} & 252 & & 4,1 & 15,8 & 33,6 & 29,6 & 16,8 \\
\hline & & & & 3,53 & 2 & 4,1 & 13,7 & 28,8 & 32,4 & 21,0 \\
\hline 11 & 254 & 1042 & 260 & & & 4,2 & 9,6 & 28,8 & 37,3 & 20,1 \\
\hline 41 & 3,54 & 1,043 & 3,60 & 3,41 & , 13 & 6,9 & 11,5 & 29,3 & 32,5 & 19,8 \\
\hline
\end{tabular}

Tabla 2. Resultados obtenidos en el item «Relaciones de amistad»

En segundo lugar situábamos aquellos elementos relacionados con la Comprensión, donde no se encuentran diferencias relevantes entre inmigrantes y españoles en casi la totalidad de sus ítems ${ }^{12}$. No obstante, como se puede ver en la tabla 3 sobre el elemento «Comprensión de códigos de conducta y usos generalmente aceptados», merece la pena comentar dos aspectos. Por un lado, la pregunta 3 Trato con respeto a mis familiares (padres y abuelos), en la que los inmigrantes obtienen mejores resultados en la respuesta «Siempre». Y por otro, resulta interesante comparar este dato con el ítem 11 Trato con respeto a mis profesores/as, en el que se obtienen puntuaciones inferiores, pero donde las diferencias entre los dos grupos desaparecen. Esto parece señalar que si bien dentro del ámbito familiar los estudiantes inmigrantes muestran mayores actitudes de respeto que sus 
compañeros, al adentrarse en el ámbito escolar este respeto disminuye y se coloca al mismo nivel que los españoles.

\begin{tabular}{|c|c|c|c|c|c|c|c|c|c|c|}
\hline \multicolumn{11}{|c|}{ «Comprensión de códigos de conducta y usos generalmente aceptados» } \\
\hline \multirow{2}{*}{ Ítem } & \multirow{2}{*}{$\overline{\mathrm{x}} \mathrm{t}$} & \multirow{2}{*}{ S } & \multirow{2}{*}{$\overline{\mathrm{X}} \mathrm{Esp}$} & \multirow{2}{*}{$\overline{\mathrm{X}} \operatorname{Inm}$} & \multirow{2}{*}{ Dif. $\overline{\mathrm{X}}$} & \multicolumn{5}{|c|}{$\% \operatorname{Esp} /$ Inm } \\
\hline & & & & & & 1 & 2 & 3 & 4 & 5 \\
\hline \multirow{2}{*}{3} & \multirow{2}{*}{4,47} & \multirow{2}{*}{, 716} & \multirow{2}{*}{4,44} & \multirow{2}{*}{4,53} & \multirow{2}{*}{,- 09} & ,3 & 1,5 & 7,4 & 36,0 & 54,9 \\
\hline & & & & & &, 5 & 1,1 & 6,5 & 28,9 & 63,0 \\
\hline \multirow{2}{*}{11} & \multirow{2}{*}{4,34} & \multirow{2}{*}{,866 } & \multirow{2}{*}{4,33} & \multirow{2}{*}{4,33} & \multirow{2}{*}{,00 } & 1,0 & 2,1 & 11,4 & 33,4 & 52,0 \\
\hline & & & & & & 1,1 & 4,1 & 11,5 & 27,0 & 56,3 \\
\hline \multirow{2}{*}{36} & \multirow{2}{*}{2,26} & \multirow{2}{*}{1,250} & \multirow{2}{*}{2,32} & \multirow{2}{*}{2,17} & \multirow{2}{*}{ 16 } & 31,9 & 26,7 & 23,9 & 11,9 & 5,5 \\
\hline & & & & & & 45,5 & 19,5 & 16,4 & 10,1 & 8,5 \\
\hline \multirow{2}{*}{38} & \multirow{2}{*}{4,18} & \multirow{2}{*}{,976 } & \multirow{2}{*}{4,25} & \multirow{2}{*}{4,07} & \multirow{2}{*}{, 18 } & 1,7 & 3,4 & 13,1 & 31,9 & 49,9 \\
\hline & & & & & & 2,5 & 5,5 & 19,6 & 27,6 & 44,9 \\
\hline
\end{tabular}

Tabla 3. Resultados obtenidos en el item «Comprensión de códigos de conducta y usos generalmente aceptados»

En tercer lugar se incluyen aspectos referidos a, donde ninguno de ellos presenta diferencias significativas entre inmigrantes y españoles, y los resultados en las medias y los porcentajes en las respuestas son casi idénticos.

En los cuatro elementos situados en torno al concepto de Respeto, tampoco se encuentran diferencias estadísticamente significativas en ninguno de ellos, excepto en el referido a la «No discriminación entre hombres y mujeres», donde inmigrantes y españoles responden de manera diversa a algunas de las preguntas planteadas. Detengámonos en tres de ellas. En el ítem 36 Evito ayudar a mi familia en las tareas de la casa, los españoles se muestran menos colaboradores que sus compañeros. Resulta también interesante observar este dato por sexos, donde las chicas inmigrantes ayudan en mayor medida en las tareas de la casa, pues más de la mitad responden que nunca evitan esta actividad, situándose por encima de los varones inmigrantes y aun a mayor distancia de los alumnos y alumnas españoles. De estos datos pueden desprenderse dos conclusiones. Por un lado, las diferencias en la disposición para colaborar en las tareas domésticas entre chicos y chicas se circunscriben al grupo de inmigrantes, mostrando porcentajes muy similares entre los estudiantes españoles de ambos sexos. Por otro, hay que destacar la mejor actitud de los inmigrantes a colaborar en las tareas del hogar, lo que parece evidenciar una mayor conciencia de que tal labor debe ser una responsabilidad compartida por todos los miembros de la familia.

Cierto interés tiene también el ítem 51 Mantengo relaciones de amistad exclusivamente con personas de mi mismo sexo, donde los españoles res- 
ponden «Nunca« en un porcentaje significativamente superior al de los inmigrantes. Es decir, afirman relacionarse en mayor medida con personas de diferente sexo que sus compañeros. Asimismo, sólo una minoría dice mantener relaciones de amistad exclusivamente con personas de su mismo sexo: 1 de cada 10 españoles y 2 de cada 10 inmigrantes.

$\mathrm{Y}$ en tercer lugar, en la pregunta 58 Creo que hombres y mujeres deben tener los mismos derechos, también existen diferencias significativas entre ambos grupos, que se observan sobre todo en la respuesta «Siempre», la cual es elegida en mayor porcentaje por los españoles que por los inmigrantes. Si atendemos a los datos entre sexos, obtenemos que el subgrupo que en mayor porcentaje respalda esta afirmación son las españolas, seguidas de las inmigrantes. A notable distancia de las primeras se encuentran sus compañeros varones que se sitúan en tercer lugar, por delante de los chicos inmigrantes también bastante distanciados de las inmigrantes. No obstante, a pesar de dichas diferencias hay que recordar que este ítem es el que mayor media presenta de todo el cuestionario y que obtiene en su respuesta «Siempre» el mayor porcentaje de respuestas en el conjunto de la muestra $(85,2 \%)$, con casi 20 puntos porcentuales de diferencia de la segunda más respondida en todos los subgrupos por sexos ya sean inmigrantes o españoles.

\begin{tabular}{|c|c|c|c|c|c|c|c|c|c|c|c|c|c|c|}
\hline \multicolumn{15}{|c|}{ «No discriminación entre hombres y mujeres» } \\
\hline \multirow[t]{3}{*}{ Ítem } & \multirow[t]{3}{*}{$\overline{\mathrm{x}} \mathrm{t}$} & \multirow[t]{3}{*}{$\mathrm{S}$} & \multirow[t]{3}{*}{$\overline{\mathrm{X}} \mathrm{Esp}$} & \multirow[t]{3}{*}{$\overline{\mathrm{X}} \mathrm{Inm}$} & \multirow[t]{3}{*}{ Dif. $\overline{\mathrm{X}}$} & \multicolumn{9}{|c|}{$\%$ Esp / Inm } \\
\hline & & & & & & \multicolumn{2}{|c|}{1} & \multicolumn{2}{|c|}{2} & \multicolumn{2}{|c|}{3} & \multicolumn{2}{|c|}{4} & 5 \\
\hline & & & & & & $\mathrm{H}$ & M & $\mathrm{H}$ & $\mathrm{M}$ & $\mathrm{H}$ & M & $\mathrm{H}$ & M & \begin{tabular}{l|l}
$\mathrm{H}$ & $\mathrm{M}$
\end{tabular} \\
\hline \multirow{4}{*}{36} & \multirow{4}{*}{2,26} & \multirow{4}{*}{1,250} & \multirow{4}{*}{2,32} & \multirow{4}{*}{2,17} & \multirow{4}{*}{,16 } & \multicolumn{2}{|c|}{31,9} & \multicolumn{2}{|c|}{26,7} & \multicolumn{2}{|c|}{23,9} & \multicolumn{2}{|c|}{11,9} & 5,5 \\
\hline & & & & & & \multicolumn{2}{|c|}{\begin{tabular}{|l|l|l|}
33,2 & 31,2 \\
\end{tabular}} & \multicolumn{2}{|c|}{\begin{tabular}{l|l|}
5,7 & 27,4
\end{tabular}} & \multicolumn{2}{|c|}{$22,925,2$} & \multicolumn{2}{|c|}{\begin{tabular}{|l|l|l}
12,7 & 10,9
\end{tabular}} & $5,5 \quad 5,4$ \\
\hline & & & & & & \multicolumn{2}{|c|}{45,5} & \multicolumn{2}{|c|}{19,5} & \multicolumn{2}{|c|}{16,4} & \multicolumn{2}{|c|}{10,1} & 8,5 \\
\hline & & & & & & 40,5 & 50,4 & 20,1 & 19,1 & 16,8 & 15,8 & 12,3 & 8,1 & \begin{tabular}{|l|l|}
10,4 & 6,6 \\
\end{tabular} \\
\hline 50 & 4.31 & 984 & 432 & 422 & 0 & 2 & 3 & 3 & 1 & 10 &, 9 & 28 & 8,2 & 55,4 \\
\hline & 4,31 & , 904 & 4,52 & 4,29 &, 02 & 3 & 8 & 2 & 4 & 13 & 3 & 21 & 5 & 59,0 \\
\hline & & & & & & 60 &, 5 & 16 &, 3 & 13 & 8 & 6 , & 1 & 3,3 \\
\hline 51 & 1,92 & 1,221 & 1,15 & 2,15 &,-- 40 & 49 &, 5 & 13 &, 3 & 17 &, 5 & 11 & 1,8 & 7,8 \\
\hline & & & & & & 1 & 1 & 2 , & 2 & 3 , & 4 & 4, & 8 & 88,5 \\
\hline & & & & & & ,9 & 1,2 & 3,7 & 6 & 6,1 & 1,0 & 8,0 & 2,0 & \begin{tabular}{|l|l|l|}
81,4 & 95,3 \\
\end{tabular} \\
\hline 58 & 4,12 & , 192 & 4,11 & 4,03 & , 15 & 2 & 6 & 2 , & 5 & 4, & 6 & 10 &, 2 & 80,1 \\
\hline & & & & & & 2,9 & 2,4 & 4,2 & 9 & 7,0 & 2,4 & 13,4 & 7,2 & \begin{tabular}{|l|l|}
72,5 & 87,0 \\
\end{tabular} \\
\hline
\end{tabular}

Tabla 4. Resultados obtenidos del item «No discriminación entre hombres y mujeres» 
Como hemos señalado, en los demás elementos del Respeto no se encuentran diferencias relevantes entre estudiantes españoles e inmigrantes en la gran mayoría de los ítems que los componen. Sin embargo, en torno al elemento "Respeto a los demás» puede resultar interesante analizar el ítem 62: Creo que las personas que llegan a España a vivir de otros países deben dejar a un lado sus costumbres y cultura de origen. En esta pregunta aparecen diferencias significativas entre inmigrantes y españoles y se observa que casi la mitad de los inmigrantes responde "Nunca», situándose a una distancia importante de sus compañeros. Unido a esto, puede decirse que este interés por conservar su cultura de origen en el país de acogida es mayor en los inmigrantes de $1^{\text {a }}$ generación, pues los de $2^{a}$ generación responden de manera muy similar a como lo hace el grupo de españoles.

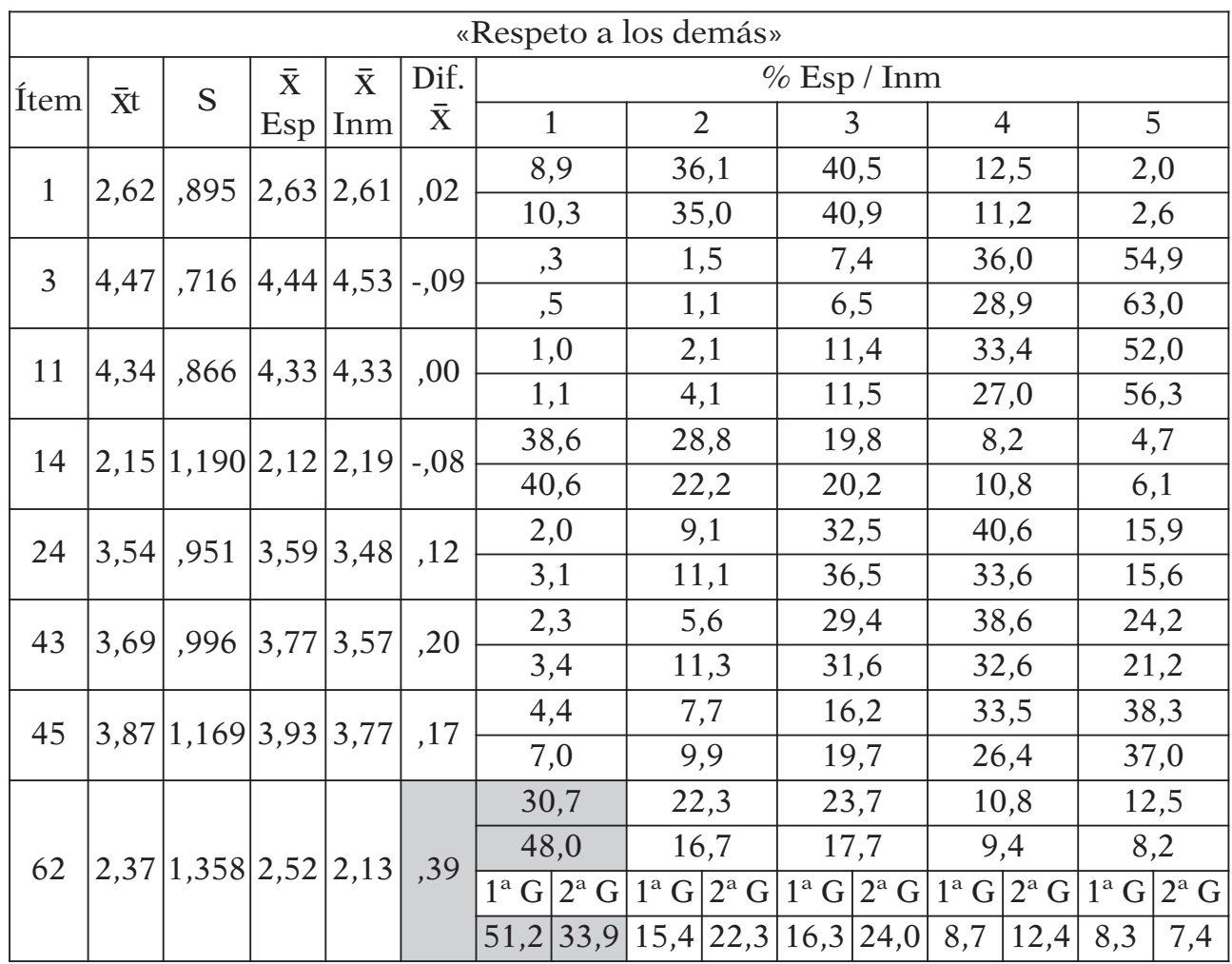

Tabla 5. Resultados obtenidos del item «Respeto a los demás»

El quinto bloque está formado por tres elementos de la competencia social que aluden a diferentes aspectos de la Generosidad, en los que se observa gran coincidencia en las respuestas de inmigrantes y españoles en la gran mayoría de los ítems. Cabe detenerse en la pregunta 52 Creo que cuan- 
do llega una persona nueva, la responsabilidad de adaptarse e integrarse es principalmente suya y no del grupo incluida en el elemento «Negociación». En ella se observan diferencias significativas entre ambos grupos, pero contrariamente a lo que podría esperarse son los inmigrantes quienes conceden mayor responsabilidad al individuo en su integración. Como puede observarse en la tabla siguiente, el 64,5\% de los españoles contesta a esta cuestión «Nunca» o «Muy pocas veces», frente al 54,3\% de los inmigrantes. Junto a esto, cabe destacar también la mayor responsabilidad que unos y otros conceden al grupo en la acogida de los recién llegados.

\begin{tabular}{|c|c|c|c|c|c|c|c|c|c|c|}
\hline \multicolumn{11}{|c|}{ «Negociación» } \\
\hline \multirow{2}{*}{ Ítem } & \multirow{2}{*}{$\overline{\mathrm{x}} \mathrm{t}$} & \multirow{2}{*}{ S } & \multirow{2}{*}{$\overline{\mathrm{X}}$ Esp } & \multirow{2}{*}{$\overline{\mathrm{X}}$ Inm } & \multirow{2}{*}{ Dif. $\overline{\mathrm{X}}$} & \multicolumn{5}{|c|}{$\% \operatorname{Esp} / \mathrm{Inm}$} \\
\hline & & & & & & 1 & 2 & 3 & 4 & 5 \\
\hline \multirow{2}{*}{24} & \multirow{2}{*}{3,54} & \multirow{2}{*}{,951 } & \multirow{2}{*}{3,59} & \multirow{2}{*}{3,48} & \multirow{2}{*}{,12 } & 2,0 & 9,1 & 32,5 & 40,6 & 15,9 \\
\hline & & & & & & 3,1 & 11,1 & 36,5 & 33,6 & 15,6 \\
\hline \multirow{2}{*}{25} & \multirow{2}{*}{4,27} & \multirow{2}{*}{,958 } & \multirow{2}{*}{4,33} & \multirow{2}{*}{4,19} & \multirow{2}{*}{,14 } & ,9 & 4,2 & 11,0 & 28,6 & 55,2 \\
\hline & & & & & & 2,6 & 5,2 & 14,2 & 26,7 & 51,3 \\
\hline \multirow{2}{*}{35} & \multirow{2}{*}{1,99} & \multirow{2}{*}{1,065} & \multirow{2}{*}{2,02} & \multirow{2}{*}{1,95} & \multirow{2}{*}{,07 } & 39,2 & 32,9 & 16,5 & 9,4 & 2,0 \\
\hline & & & & & & 45,3 & 26,3 & 19,1 & 6,4 & 2,8 \\
\hline \multirow{2}{*}{52} & \multirow{2}{*}{2,31} & \multirow{2}{*}{1,221} & \multirow{2}{*}{2,24} & \multirow{2}{*}{2,41} & \multirow{2}{*}{,- 17} & 32,7 & 31,8 & 21,1 & 7,2 & 7,2 \\
\hline & & & & & & 31,9 & 22,4 & 26,8 & 10,4 & 8,5 \\
\hline
\end{tabular}

Tabla 6. Resultados obtenidos del item «Negociación»

Por último, la mayoría de las preguntas incluidas en el bloque que alude a la interculturalidad no muestran diferencias significativas entre los estudiantes de origen español e inmigrante. No obstante, puede resultar interesante ver con detalle alguno de estos ítems.

Por definición, para que la interculturalidad sea una realidad es necesario que el discernimiento de las aportaciones de las culturas se traduzca en un intercambio cultural entre la cultura mayoritaria y alguna de las otras culturas presentes hoy en nuestras sociedades. Por ello, incluimos en los cuestionarios varias preguntas en torno al interés por el conocimiento de los valores culturales de las personas con las que convivimos y de los propios, pues si no se conoce en profundidad la propia cultura ¿cómo responderemos cuando en el intercambio después del «recibir» llegue el momento del «dar»? Por otro lado, como ya apuntamos, conocer la propia cultura es el paso imprescindible para poder respetarla y evaluarla, así como el refuerzo de los anclajes que nos permitirán forjarnos una personalidad madura preparada para poder respetar y evaluar la cultura del otro (Pérez Juste, 2008; Merry, 2011; García López, 2003). El ítem 53 Me intereso por conocer los valores que 
definen el modo de vida de los españoles se encamina a este objetivo. Los resultados obtenidos muestran diferencias estadísticamente significativas aunque poco relevantes entre ambos grupos obteniendo una mayor puntuación los españoles. Sin embargo, mayor atención merece la baja puntuación obtenida por ambos grupos en esta cuestión, donde el mayor porcentaje de respuestas se sitúa en la medida central.

\begin{tabular}{|c|c|c|c|c|c|c|c|c|c|c|}
\hline \multicolumn{11}{|c|}{ «Comunicación intercultural» } \\
\hline \multirow{2}{*}{ Ítem } & \multirow{2}{*}{$\overline{\mathrm{x}} \mathrm{t}$} & \multirow{2}{*}{$\mathrm{S}$} & \multirow{2}{*}{$\overline{\mathrm{X}} \operatorname{Esp}$} & \multirow{2}{*}{$\overline{\mathrm{X}} \operatorname{Inm}$} & \multirow{2}{*}{ Dif. $\overline{\mathrm{X}}$} & \multicolumn{5}{|c|}{$\%$ Esp / Inm } \\
\hline & & & & & & 1 & 2 & 3 & 4 & 5 \\
\hline \multirow{2}{*}{10} & \multirow{2}{*}{3,62} & \multirow{2}{*}{,972 } & \multirow{2}{*}{3,69} & \multirow{2}{*}{3,53} & \multirow{2}{*}{,16 } & 1,8 & 7,4 & 30,8 & 39,9 & 20,0 \\
\hline & & & & & & 3,5 & 11,1 & 31,9 & 36,0 & 17,5 \\
\hline \multirow{2}{*}{25} & \multirow{2}{*}{4,27} & \multirow{2}{*}{,958 } & \multirow{2}{*}{4,33} & \multirow{2}{*}{4,19} & \multirow{2}{*}{, 14} & 9 & 4,2 & 11,0 & 28,6 & 55,2 \\
\hline & & & & & & 2,6 & 5,2 & 14,2 & 26,7 & 51,3 \\
\hline \multirow{2}{*}{26} & \multirow{2}{*}{3,95} & \multirow{2}{*}{1,030} & \multirow{2}{*}{3,93} & \multirow{2}{*}{3,99} & \multirow{2}{*}{,- 06} & 2,1 & 7,1 & 21,5 & 34,3 & 35,0 \\
\hline & & & & & & 2,0 & 7,4 & 21,7 & 27,8 & 41,2 \\
\hline \multirow{2}{*}{32} & \multirow{2}{*}{3,86} & \multirow{2}{*}{1,043} & \multirow{2}{*}{3,83} & \multirow{2}{*}{3,91} & & 2,6 & 8,1 & 23,6 & 35,3 & 30,4 \\
\hline & & & & &,- 09 & 2,6 & 7,5 & 21,4 & 32,8 & 35,7 \\
\hline & & & & & & 2,3 & 5,6 & 29,4 & 38,6 & 24,2 \\
\hline 43 & 3,69 & ,996 & 3,11 & 3,51 &, 20 & 3,4 & 11,3 & 31,6 & 32,6 & 21,2 \\
\hline & & & & & & 63,1 & 19,1 & 8,8 & 5,3 & 3,8 \\
\hline 46 & 1,64 & 1,086 & 1,68 & 1,58 & ,09 & 71,8 & 11,2 & 7,7 & 5,3 & 3,9 \\
\hline & & & & & & 2,3 & 3,1 & 10,9 & 28,2 & 55,5 \\
\hline 50 & 4,31 & 984 & 4,32 & 4,29 & 02 & 3,8 & 2,4 & 13,3 & 21,5 & 59,0 \\
\hline 53 & 318 & 1141 & 328 & 305 & 23 & 6,8 & 15,2 & 39,1 & 21,1 & 17,7 \\
\hline 53 & 3,18 & 1,141 & 3,28 & 3,05 & ,23 & 11,6 & 17,4 & 37,7 & 21,3 & 12,0 \\
\hline & & & & & & 10,6 & 18,4 & 28,6 & 24,4 & 18,0 \\
\hline 54 & 3,26 & 1,238 & 3,21 & 3,35 &,- 15 & 9,1 & 14,6 & 31,5 & 21,6 & 23,3 \\
\hline & & & & & & 45,8 & 26,4 & 14,1 & 8,6 & 5,1 \\
\hline 59 & 1,98 & 1,211 & 2,01 & 1,95 & 06 & 54,9 & 15,1 & 16,6 & 7,0 & 6,4 \\
\hline 62 & 237 & 1358 & 2.52 & 2,13 & 39 & 30,7 & 22,3 & 23,7 & 10,8 & 12,5 \\
\hline 02 & 2,31 & 1,358 & 2,52 & 2,13 & , 39 & 48,0 & 16,7 & 17,7 & 9,4 & 8,2 \\
\hline
\end{tabular}

Tabla 7. Resultados obtenidos del item «Comunicación intercultural»

Pasemos ahora a analizar la segunda condición necesaria para constatar nuestra hipótesis sobre la transculturalidad de la competencia social, que consistía en conocer si los alumnos inmigrantes perciben de manera diferente los aspectos principales de dicha competencia ${ }^{13}$. 
Los alumnos inmigrantes tienden a responder mayoritariamente que «Algunas veces» sus percepciones de los diferentes componentes evaluados de la competencia social, coinciden con las de los españoles. Visto así, podría concluirse que no es posible afirmar si coinciden o no las visiones sobre la competencia social al no haber una clara mayoría en un sentido u otro. Sin embargo, una reflexión más detenida apunta en otra dirección, pues aunque se ha utilizado la misma escala de frecuencias que para el resto de preguntas de la segunda parte del cuestionario, la respuesta «Algunas veces», se acerca más a la falta de similitud entre conceptos que a la coincidencia entre ellos. Por ello, si vemos cómo más de la mitad de los alumnos inmigrantes responden que sólo "Algunas veces», "Muy pocas veces» o «Nunca» en todos los grupos de elementos evaluados, podemos aceptar las diferencias en la concepción de la competencia social entre españoles e inmigrantes.

La pregunta 48 Tengo una manera de relacionarme con mis compañeros/as muy parecida a la que es habitual en España, debe observarse de manera algo diferente al resto de las incluidas en este grupo, pues en ella lo que se pide comparar no es un concepto abstracto, sino la manera concreta de relacionarse con los demás. Así pues, casi la mitad de los alumnos inmigrantes $(44,4 \%)$, dicen relacionarse con sus compañeros de forma similar a como lo hacen los españoles «La mayoría de las veces» o «Siempre». No en vano, obtienen la media más alta de los elementos estudiados en este aspecto. Esto contribuye a mostrar que si bien en el plano de los conceptos solemos subrayar las diferencias con los otros, cuando nos referimos a las acciones concretas aparecen con mayor fuerza las semejanzas.

\begin{tabular}{|c|c|c|c|c|c|c|c|}
\hline \multicolumn{7}{|c|}{ Comparación de los principales aspectos de la competencia social } \\
(Respuestas de los alumnos inmigrantes) \\
\hline Ítem & $\overline{\mathrm{X}}$ & $\mathrm{S}$ & 1 & 2 & 3 & 4 & 5 \\
\hline 12 & 3,15 & 1,135 & 9,7 & 16,3 & 35,8 & 25,7 & 12,5 \\
\hline 23 & 2,94 & 1,096 & 10,8 & 22,8 & 36,6 & 21,6 & 8,2 \\
\hline 37 & 2,89 & 1,118 & 12,7 & 21,1 & 39,9 & 17,0 & 9,3 \\
\hline 40 & 3,17 & 1,075 & 7,7 & 16,4 & 38,5 & 26,3 & 11,2 \\
\hline 48 & 3,32 & 1,155 & 8,5 & 12,7 & 34,3 & 27,0 & 17,4 \\
\hline $\mathrm{x}^{-}$total & 3,09 & \multicolumn{7}{|c}{} & \\
\hline
\end{tabular}

Tabla 8. Comparación de resultados obtenidos de la competencia social 


\subsection{Valoración de los inmigrantes de la competencia social en el grupo mayoritario}

Junto a los aspectos descritos, consideramos interesante conocer la valoración que los alumnos inmigrantes realizan sobre la presencia de los principales elementos de la competencia social en la cultura mayoritaria.

En la mayor parte de los elementos evaluados la valoración de los alumnos inmigrantes se sitúa por encima del 3 en la escala de 5. La puntuación más alta alude a la actitud de apertura y acogimiento de los españoles, donde casi la mitad de los inmigrantes consideran a los españoles personas abiertas y acogedoras «La mayoría de las veces» y «Siempre». La más baja es la que se concede a la afirmación de que los españoles son personas respetuosas con los demás -ítem 55-, donde un 35,5\% (respuestas 1 y 2) tiene una opinión negativa al respecto.

\begin{tabular}{|c|c|c|c|c|c|c|c|c|c|c|}
\hline \multicolumn{11}{|c|}{ Valoración de la competencia social en el grupo mayoritario } \\
\hline \multirow{2}{*}{ Ítem } & \multirow{2}{*}{$\overline{\mathrm{x}} \mathrm{t}$} & \multirow{2}{*}{ S } & \multirow{2}{*}{$\overline{\mathrm{X}} \operatorname{Esp}$} & \multirow{2}{*}{$\overline{\mathrm{X}} \mathrm{Inm}$} & \multirow{2}{*}{ Dif. $\overline{\mathrm{X}}$} & \multicolumn{5}{|c|}{$\%$ Esp / Inm } \\
\hline & & & & & & 1 & 2 & 3 & 4 & 5 \\
\hline \multirow{2}{*}{9} & \multirow{2}{*}{3,29} & \multirow{2}{*}{1,111} & \multirow{2}{*}{3,43} & \multirow{2}{*}{3,10} & \multirow{2}{*}{,33 } & 6,7 & 9,8 & 34,4 & 32,2 & 16,9 \\
\hline & & & & & & 9,7 & 18,7 & 34,0 & 27,5 & 10,2 \\
\hline \multirow{2}{*}{21} & \multirow{2}{*}{3,20} & \multirow{2}{*}{1,012} & \multirow{2}{*}{3,29} & \multirow{2}{*}{3,06} & \multirow{2}{*}{,23 } & 3,6 & 13,0 & 48,2 & 21,7 & 13,5 \\
\hline & & & & & & 7,3 & 20,9 & 39,4 & 23,4 & 9,0 \\
\hline \multirow{2}{*}{27} & \multirow{2}{*}{3,55} & \multirow{2}{*}{1,013} & \multirow{2}{*}{3,65} & \multirow{2}{*}{3,41} & \multirow{2}{*}{,24 } & 2,2 & 6,8 & 37,1 & 32,3 & 21,6 \\
\hline & & & & & & 5,2 & 13,0 & 34,0 & 31,1 & 16,6 \\
\hline \multirow{2}{*}{33} & \multirow{2}{*}{3,29} & \multirow{2}{*}{1,454} & \multirow{2}{*}{3,39} & \multirow{2}{*}{3,13} & \multirow{2}{*}{,27 } & 3,5 & 14,6 & 39,8 & 27,3 & 14,7 \\
\hline & & & & & & 8,0 & 18,6 & 36,8 & 26,0 & 10,6 \\
\hline \multirow{2}{*}{44} & \multirow{2}{*}{3,11} & 1005 & 224 & 201 & 2 & 5,7 & 16,4 & 41,2 & 22,0 & 14,8 \\
\hline & & 1,095 & 3,24 & 2,91 & כ3, & 11,5 & 23,3 & 36,3 & 20,6 & 8,4 \\
\hline 55 & 304 & 1101 & 315 & 288 & 27 & 6,9 & 17,7 & 42,6 & 19,1 & 13,7 \\
\hline כว & 3,04 & 1,101 & 3,15 & 80 & , 21 & 12,6 & 22,9 & 35,8 & 20,6 & 8,0 \\
\hline 57 & 428 & 1042 & 447 & 399 & 48 & 1,9 & 3,8 & 8,3 & 17,2 & 68,8 \\
\hline ו & 7,20 & דרט, & ITI & נונינד & 40 & 2,6 & 10,0 & 17,9 & 24,5 & 44,9 \\
\hline 61 & 322 & 101 & 235 & 304 & 21 & 5,5 & 12,0 & 40,1 & 27,2 & 15,3 \\
\hline 01 & $3, \angle 2$ & 1,094 & כנ, & 3,04 & 10, & 10,5 & 19,7 & 36,6 & 22,3 & 10,9 \\
\hline$\overline{\mathrm{X}}$ totales: & 3,37 & & 3,49 & 3,19 & & & & & & \\
\hline
\end{tabular}

Tabla 9. Valoración de la competencia social en el grupo mayoritario 
Si comparamos las respuestas entre españoles e inmigrantes vemos que existen diferencias en la valoración del grupo mayoritario; sin embargo, sólo el ítem 57 tiene cierta relevancia al mostrar la mayor conformidad de los españoles en España que los inmigrantes. También puede resultar interesante observar que los alumnos de ambos grupos coinciden en los elementos que sitúan en el lugar más alto y en el más bajo.

\subsection{Datos personales y competencia social}

Si observamos los datos recogidos en la parte descriptiva del cuestionario, a saber, sexo, edad, tipo de centro, curso, nota media de los últimos 2 años, $\mathrm{n}^{\circ}$ de repeticiones de curso, nivel de estudios de los padres, creencias religiosas - potestativo-, inmigrante de $1^{\mathrm{a}} \mathrm{o} 2^{\mathrm{a}}$ generación $^{14,}$ y los resultados en el desarrollo de los diferentes elementos de la competencia social, no puede encontrarse una variable que repercuta significativamente en todos los elementos de la competencia social o que muestre una tendencia clara hacia algunas de sus categorías con una correlación estadística media o alta. Sólo puede hablarse de ligeras tendencias, donde la más significativa es la detectada en la variable sexo.

Las alumnas obtienen puntuaciones más altas en casi todos los elementos de la competencia social, algo común en muchos países. Las mayores disparidades se observan en las «Relaciones de amistad» y especialmente en los ítems 2 y 7 -los únicos con diferencia de medias mayores a 0,5-, que muestran cómo las chicas se interesan por las preocupaciones de sus amigos/as y comparten las suyas en mayor medida que los chicos.

\begin{tabular}{|c|c|c|c|}
\hline \multicolumn{4}{|c|}{ Sexo } \\
\hline Elementos & $\overline{\mathrm{X}} \mathrm{V}$ & $\overline{\mathrm{X}} \mathrm{M}$ & Dif $\overline{\mathrm{X}}$ \\
\hline Relaciones de amistad & 3,39 & 3,80 &,- 41 \\
\hline $\begin{array}{c}\text { Comprensión de códigos de conducta } \\
\text { y usos generalmente aceptados }\end{array}$ & 3,85 & 4,01 &,- 16 \\
\hline $\begin{array}{c}\text { Expresión y comprensión de puntos } \\
\text { de vista diferentes }\end{array}$ & 3,93 & 4,22 &,- 29 \\
\hline Empatía & 3,42 & 3,72 &,- 3 \\
\hline Organización del trabajo & 2,78 & 2,91 &,- 13 \\
\hline
\end{tabular}




\begin{tabular}{|c|c|c|c|}
\hline Gestión de estrés y frustración & 2,77 & 2,67 &, 01 \\
\hline $\begin{array}{c}\text { No discriminación entre hombres } \\
\text { y mujeres }\end{array}$ & 3,57 & 3,84 &,- 27 \\
\hline Tolerancia & 3,76 & 4,08 &,- 32 \\
\hline Superación de prejuicios & 3,57 & 3,79 &,- 22 \\
\hline Respeto a los demás & 3,36 & 3,57 &,- 21 \\
\hline Comunicación constructiva & 3,02 & 3,1 &,- 08 \\
\hline Actitud de colaboración & 3,43 & 3,69 &,- 26 \\
\hline Negociación & 3,25 & 3,32 &,- 07 \\
\hline Comunicación intercultural & 3,43 & 3,67 &,- 24 \\
\hline
\end{tabular}

\begin{tabular}{|c|c|c|c|c|c|c|c|c|}
\hline \multirow{2}{*}{$\begin{array}{c}\text { Ítems dif } \\
\overline{\mathrm{X}} \geq 0,5\end{array}$} & \multirow{2}{*}{$\overline{\mathrm{X}} \mathrm{V}$} & \multirow{2}{*}{$\overline{\mathrm{X}} \mathrm{M}$} & \multirow{2}{*}{$\operatorname{Dif} \overline{\mathrm{X}}$} & \multicolumn{6}{|c|}{$\%$ V/M } \\
\cline { 5 - 9 } & & & & 1 & 2 & 3 & 4 & 5 \\
\hline \multirow{2}{*}{2} & \multirow{2}{*}{3,13} & \multirow{2}{*}{3,83} & \multirow{2}{*}{,- 70} & 8,3 & 21,1 & 31,0 & 28,4 & 11,2 \\
\cline { 5 - 9 } & & & & 1,6 & 9,8 & 20,3 & 40,2 & 28,2 \\
\hline \multirow{2}{*}{3,82} & 4,49 & \multirow{2}{*}{,- 67} & 2,7 & 7,0 & 24,3 & 37,9 & 28,1 \\
\cline { 5 - 9 } & & & &, 5 & 1,9 & 6,5 & 30,4 & 60,8 \\
\hline
\end{tabular}

Tabla 10. Valoración de la competencia social a partir de la variable sexo

\section{CONCLUSIONES}

El estudio que acabamos de presentar muestra cómo los diferentes elementos de la competencia social, tal y como se definen por, son vistos de manera diversa por alumnos españoles e inmigrantes. Sin embargo, no pueden encontrarse diferencias significativas en su desarrollo operativo. Es decir, aunque utilicen diferentes denominaciones, los comportamientos de respeto, comprensión, responsabilidad, etc. no se presentan de manera diferente en unos y otros, por lo que cabría afirmar su transculturalidad. 
La evaluación de la competencia social puede servirnos para hacer efectivo uno de los fundamentos de la interculturalidad y reconocer «lo valioso» que se encuentra presente en la cultura del otro. Como afirman Suárez Orozco y Suárez Orozco $(2003,17)$, «las actitudes positivas iniciales de los inmigrantes constituyen un recurso valioso que debe cultivarse. En cuanto sociedad, nos convendría al máximo aprovechar sus energías». Así pues, los resultados encontrados recomiendan que los alumnos españoles aprendan del mayor respeto a padres y abuelos que los alumnos inmigrantes afirman tener, y nos han de llevar a preguntarnos sobre las razones por las que el trato recibido por los profesores ha llegado a ser significativamente menos respetuoso, que el que los alumnos inmigrantes profesan por sus ascendientes. Asimismo, la menor disposición de los estudiantes españoles a colaborar en las tareas de la casa en comparación con sus compañeros, nos desvela también un aspecto sobre el que incidir desde el ámbito educativo.

Unido a esto, los resultados obtenidos señalan que la tarea de educación en la no discriminación entre hombres y mujeres debe situarse entre los objetivos hacia los que avanzar con quienes poseen origen foráneo.

También en relación con el respeto se encuentra el mantenimiento de las costumbres y cultura de origen en el país de acogida, donde como hemos visto, existen diferencias destacables entre estudiantes inmigrantes y españoles. Esta evidencia del fracaso del modelo asimilacionista abre otra vía de trabajo educativo guiado por la importancia del respeto a los elementos identitarios de los otros.

El análisis de los aspectos relativos a la amistad muestra una ligera tendencia en la que los españoles podrían presentar mayor facilidad para establecer amistades que sus compañeros inmigrantes, lo que requiere un especial cuidado en la promoción de estas relaciones, en orden a evitar que el proceso migratorio y la adaptación al país de acogida no se conviertan en un obstáculo insuperable para el establecimiento de vínculos sólidos y permanentes con sus iguales.

Resulta también preocupante el bajo interés de los españoles por los elementos culturales propios, pues si concebimos la interculturalidad como un intercambio deliberativo cultural, el conocimiento e interés por la propia cultura debe ser parte fundamental de dicho intercambio y, por lo tanto, objeto de la acción educativa. Así las cosas, no es de extrañar que los inmigrantes presenten escaso interés por la cultura española, si quienes a ella pertenecen no lo hacen con empeño.

Finalmente, cabría señalar que si bien este estudio indica algunas pistas básicas para dar una respuesta educativa al pluralismo social de nuestros 
días, es obvio que necesitamos muchos más trabajos, quizá con diseños cualitativos o multimétodos, dirigidos a una mayor delimitación de esos valores y elementos de la competencia social que se han mostrado aquí con carácter transcultural, pero que pueden presentar peculiaridades propias dependiendo del origen cultural específico, más allá del amplio conglomerado que se engloba bajo la denominación «inmigrantes». 


\section{NOTAS}

1 Todo trabajo de campo debe incluir agradecimientos. Por un lado, a los centros educativos del municipio de Madrid que nos abrieron las puertas de sus aulas y nos concedieron su valioso tiempo. Por otro lado, a los alumnos de la licenciatura de Pedagogía de , de la materia de Política y Legislación Educativa en el curso 2009-2010, que colaboraron en las visitas a los centros.

2 A este respecto pueden ser de interés los discursos de la Canciller alemana Angela Merkel sobre el fracaso del multiculturalismo en el país germano, disponible en http://www.elmundo.es/elmundo/2010/10/17/internacional/1287269452.html [consulta 2011, 27 de noviembre], o el del Primer Ministro británico David Cameron, quien proponía una nueva identidad británica que pudiera servir de referencia a los jóvenes inmigrantes. Disponible en http://www.number10.gov.uk/news/pms-speech-at-munich-security-conference/ [consulta 2011, 27 de noviembre].

3 Hace años tuvieron mucho eco algunas obras que denunciaron el error de la equivalencia de las culturas, como los libros de Finkielkraut, A. (1987). La derrota del pensamiento. Barcelona: Anagrama, y Revel, J. F. (1989) El conocimiento inútil. Madrid: Planeta.

4 A título de ejemplo señalemos algunos trabajos de nuestro entorno cercano: Gairín, J. e Iglesias, E. (2010). El programa curricular en contextos escolares con fuerte presencia de los alumnos de familia inmigrante. Bordón, 62 (I), 61-75; Mafokozi, J. (2010). Resistencia cultural en el contexto socioeducativo: Un estudio empírico en de Madrid. C\&E. Cultura y Educación, 22:1, 99-120; Esteve, J. M., Ruiz Román, C. y Rascón, M . T. (2008). La construcción de la identidad en los hijos de inmigrantes marroquíes. Revista Española de Pedagogía, LXVI, 241, 489-508; etc.

5 Un estudio similar fue realizado en la ciudad de Melilla hace unos años, motivado por la pregunta «¿cuáles son los valores que deben fundamentar un Currículum Intercultural Islámico-Occidental en la Ciudad de Melilla?»(Arroyo, 2000, 322).

6 Para la operativización de los elementos de la competencia social nos han sido de gran ayuda los cuestionarios incluidos en Isaacs (2003).

7 Debido a las dificultades de abstracción que podrían entrañar los conceptos de «comprensión» y «respeto», se excluyeron de este tipo de preguntas y se incluyó el concepto de «esfuerzo».

8 Para una clasificación similar de valores de carácter intercultural ver García López y Sales (1997).

9 Los seis valores indicados junto al del «esfuerzo» incluido en el bloque de preguntas comparativas y otra pregunta indirecta sobre esta cuestión: «Me siento a gusto en España».

10 En este grupo se incluyen también los alumnos que señalaron como origen cultural de sus padres «Españoles-gitanos». Si bien en un principio pretendíamos diferenciar este grupo del mayoritario, la escasa muestra obtenida con uno de sus dos padres gitanos $(0,6 \%)$ impide hacer inferencias al respecto.

11 Considérese aquí que se ha realizado la adaptación pertinente de las preguntas formuladas en negativo para posibilitar su comparación con las preguntas formuladas en positivo.

12 Para no saturar de tablas el artículo, sólo se incluyen aquellas en las que se han hallado resultados significativos. Para mayor detalle pueden contactar con los autores en las direcciones que se adjuntan. 
13 Aunque nuestro objetivo era conocer la opinión del grupo de inmigrantes en relación a este tema, consideramos inadecuado -y poco operativo- realizar dos tipos diferenciados de cuestionarios para inmigrantes o españoles, por lo que se entregó el mismo cuadernillo a todos los alumnos.

14 Se recogieron algunos datos más, pero por razones de espacio no pueden ser reflejados aquí. 


\section{ANEXO}

1. Actúo sin pensar mucho en las consecuencias positivas y negativas de mis acciones.

2. Comparto con los/las amigos/as mis preocupaciones.

3. Trato con respeto a mis familiares (padres y abuelos).

4. Me esfuerzo por tener amigos/as, pues creo que eso es muy importante en mi vida.

5. Sólo estudio antes de los exámenes.

6. Critico a otras personas cuando no están presentes.

7. Me intereso por las preocupaciones de mis amigos/as.

8. Cuando algo no me sale bien me enfado y dejo de hacerlo.

9. Pienso que los/las españoles/as se caracterizan por ser amigables.

10. Intento compartir mis valores con los demás.

11. Trato con respeto a mis profesores/as.

12. Mi idea de la amistad coincide con la idea de amistad de los/las españoles/as.

13. Trato de ver las cosas desde el punto de vista del otro/a para poder comprenderle mejor.

14. Al elegir a mis amigos/as tengo en cuenta primeramente lo que me interesa.

15. Intento comprarme todo lo que me gusta.

16. Creo que cada persona es diferente a las demás y que, por tanto, es normal que tenga puntos de vista o necesidades distintos de los míos.

17. Me esfuerzo por conocer mis cualidades y mis defectos.

18. No pretendo echar la culpa a los demás de las consecuencias de mis errores.

19. Les digo a mis amigos/as lo que pienso que deben mejorar en su comportamiento.

20. Me empeño en cumplir mis compromisos aunque me cueste esfuerzo.

21 Pienso que los/las españoles/as procuran ser comprensivos/as con los demás.

22. Cuando tomo una decisión me empeño en llevarla hasta el final aunque sepa que estoy equivocado/a.

23. Mi idea de la responsabilidad coincide con la idea de responsabilidad de la mayor parte de los españoles.

24. Reflexiono sobre las circunstancias del momento y los intereses de los demás a la hora de llevar a cabo mis proyectos. 
25. Aunque tengo mis ideas y creencias, soy capaz de dialogar con personas que piensen de manera diferente a mí.

26. Me gusta conocer y estudiar ideas nuevas.

27. Pienso que los/las españoles/as son personas abiertas y acogedoras.

28. Intento dar lo mejor de mí mismo/a en lo que hago para hacer un buen trabajo.

29. Pienso que la mayoría de las cosas realmente valiosas sólo se consiguen poniendo empeño y esfuerzo.

30. Suelo quejarme ante las dificultades, aunque éstas sean pequeñas.

31. Dejo las tareas para última hora.

32. Estoy abierto/a al aprendizaje de lo positivo que veo en quienes son de otras naciones.

33. Considero que los/las españoles/as valoran la importancia del esfuerzo y el sacrificio.

34. Me intereso por las preocupaciones y necesidades de quienes tienen menos amigos en mi clase.

35. Me cuesta mucho prestar algo.

36. Evito ayudar a mi familia en las tareas de la casa.

37. Mi idea del esfuerzo y el sacrificio coincide con la que tienen la mayoría de los/las españoles/as.

38. Creo que es necesario para la convivencia conocer y respetar las normas de comportamiento propias del lugar donde esté, siempre que no sean contrarias a los derechos humanos.

39. Ayudo a los compañeros/as que tienen dificultades para hacer amistades a que participen en las actividades del grupo.

40. Pienso que mi idea de la generosidad coincide con la idea de generosidad de los/las españoles/as.

41. Ayudo a mis compañeros/as cuando tienen dificultades en las tareas escolares.

42. Pienso que las diferencias de raza no deben ser motivo para que unas personas tengan menos derechos que otras.

43. Me intereso por conocer las circunstancias y características de mis compañeros/as.

44. Creo que la generosidad es una característica de los/las españoles/as.

45. Cuando estoy en un grupo, procuro evitar cualquier conversación que pueda hacer que alguien se sienta herido/a o apartado/a. 
46. Evito relacionarme con personas de otras nacionalidades.

47. Creo que el trabajo en equipo y la colaboración con los/las compañeros/as es un buen modo de comportamiento.

48. Tengo una manera de relacionarme con mis compañeros/as muy parecida a la que es habitual en España.

49. Pienso que las diferencias en el país de origen no deben ser motivo para que unas personas tengan menos derechos que otras.

50. Pienso que como cada persona es diferente a las demás, todas pueden aportar algo valioso.

51. Mantengo relaciones de amistad exclusivamente con personas de mi mismo sexo.

52. Creo que cuando llega una persona nueva, la responsabilidad de adaptarse e integrarse es principalmente suya y no del grupo.

53. Me intereso por conocer los valores que definen el modo de vida de los españoles.

54. Comparto con mis compañeros/as los elementos más positivos que caracterizan a mi propia cultura y a mi país de origen.

55. Pienso que los/las españoles/as se caracterizan por ser personas respetuosas con los demás.

56. Juzgo a las personas principalmente por su aspecto externo o lo que «se dice» de ellas.

57. Me siento a gusto en España.

58. Creo que hombres y mujeres deben tener los mismos derechos.

59. Tengo muchas dificultades para establecer relaciones de amistad con personas de otra raza o de otro país distinto del mío.

60 Pienso que las diferencias de religión no deben ser motivo para que unas personas tengan menos derechos que otras.

61. Pienso que los/las españoles/as se esfuerzan por asumir sus responsabilidades.

62. Creo que las personas que llegan a España a vivir de otros países deben dejar a un lado sus costumbres y cultura de origen. 


\section{REFERENCIAS BIBLIOGRÁFICAS}

Arroyo, R. (2000). Criterios para la elaboración de un currículum intercultural en Melilla: un estudio multimétodo. Revista Española de Pedagogía, LVIII (216), 313-340.

Ayuntamiento de Madrid (2010). Padrón Municipal de Habitantes a 1 de enero de 2010. Datos provisionales [en línea]. Disponible en: www.madrid.es [consulta 2010, 10 de agosto].

Banks, J. A. (2009). Multicultural education: Dimensions and paradigms, en Banks, J. A. (Ed.) The Routledge International Companion to Multicultural Education. London: Routledge, 9-32.

Banks, J. A. (2006). Race, Culture and Education. London: Routledge.

Banks, J. A. (2003). Multicultural Education, Historical Development, Dimensions, and Practice, en Banks, J. A. y McGee Banks, C. A. (Eds.) Handbook of Research on Multicultural Education. London: Jossey-Bass, 3-29.

Barrio, J. M. (2007). ¿Es posible un diálogo entre culturas? Disponible en: http://www.es.catholic.net/temacontrovertido/326/2780/articulo.php?id=3340 5 [consulta 2010, 20 de agosto].

Ben-Porath, S. (2012). Education for Shared Fate Citizenship, en Allen, D. y Reich, R. (Eds.) Justice, Education, and Democracy. Chicago: Chicago University Press, 1-27.

Boghossian, P. (2009). Miedo al conocimiento. Contra el relativismo y el constructivismo. Madrid: Alianza.

Comunidad de Madrid (2009). Estadística de la enseñanza de de Madrid 2008-2009 [en línea]. Madrid: Consejería de Educación. Disponible en: www.madrid.org [consulta 2010, 24 de septiembre].
Consejo de Europa (2008). Libro Blanco sobre el Diálogo Intercultural. Estrasburgo: Consejo de Europa. Disponible en www.coe.int/dialogue [consulta 2010, 31 de marzo].

Corral, Y. (2009). Validez y confiabilidad de los instrumentos de investigación para la recolección de datos. Revista Ciencias de la Educación, 19 (33), 228247.

Cea D Ancona, M. A. (2009). La compleja detección del racismo y la xenofobia a través de encuesta. Un paso adelante en su medición. Revista Española de Investigaciones Sociológicas, 125, 13-45.

Diario Oficial de (2006). Recomendación del Parlamento Europeo y del Consejo de 18 de diciembre de 2006 sobre las competencias clave para el aprendizaje permanente (2006/962/CE). Disponible en: http://eur-lex.europa.eu/LexUriServ/LexUriServ.do?uri=OJ:L:2006:394:0010:001 8:ES:PDF [consulta 2011, 11 de enero].

Esteve, J. M. (2005). Calidad y aceptación de la diversidad frente a la pedagogía de la exclusión, en Soriano, E. (Coord.) La interculturalidad como factor de calidad educativa. Madrid: La Muralla, 77-117.

García Amilburu, M. y Ruiz Corbella, M. (2009). ¿Tiene futuro la filosofía de la educación en un diseño de educación en competencias?, en Ibáñez-Martín, J. A. (Coord.) Educación, conocimiento y justicia. Madrid: Dykinson, 101-126.

García López, R. (2003). Formación del profesorado en pedagogía intercultural: contenidos actitudinales. ESE: Estudios sobre Educación, 4, 47-66.

García López, R. y Sales, A. (1997). La educación intercultural y la formación de actitudes. Programa pedagógico para desarrollar actitudes intercultu- 
rales. Revista Española de Pedagogía, LV (207), 317-336.

Hansen, D. T. (2010). Chasing Butterflies Without a Net: Interpreting Cosmopolitanism. Studies in Philosophy of Education, 29, 151-166.

Harris, S. (2011). The University in Translation. Internationalizing Higher Education. London: Continuum.

Ibáñez-Martín, J. A. (2009). Educación y derechos humanos, en Ibáñez-Martín, J. A. (Coord.) Educación, Conocimiento y Justicia. Madrid: Dykinson, 13-22.

Isaacs, D. (2003). La educación de las virtudes humanas y su evaluación. Pamplona: EUNSA.

Lora-Tamayo, G. (2009). España y la inmigración extranjera. Segundas Lenguas e inmigración en red [en línea], 3, 3-25. Disponible en: http://www.segundaslenguaseinmigracion.es/ [consulta 2011, 11 de enero].

Maalouf, A. (2000). Identidades asesinas. Madrid: Alianza.

Merry, M. S. (2011). Equality, self-respect and voluntary separation. Critical Review of International Social and Political Philosophy, 9 (1), 1-22.

Merry, M. S. y de Ruyter, D. J. (2011). The relevance of cosmopolitanism for moral education. Journal of Moral Education, 40 (1), 1-18.

May, S. (2009). Critical multiculturalism and education, en Banks, J. A. (Ed.) The Routledge International Companion to Multicultural Education. London: Routledge, 33-48.

Némirovsky, I. (2009). El Maestro de Almas. Barcelona: Salamandra.

Olveira Olveira, M. E. y Santos Rego, M. A. (2000). Interculturalismo en Europa: el referente de las segundas generaciones españolas en Francia. Revista Española de Pedagogía, LVIII (216), 341-358.

Parekh, B. (2006). Rethinking Multiculturalism: Cultural Diversity and Political Theory. Basingstoke: Palgrave.

Parra, J. (2011). Globalización, pluralismo e interculturalidad. Stadium, 51 (1), 4 - 22 .

Pérez Juste, R. (2008). Educación integral, sociedades multiculturales e interculturalidad: la respuesta de la educación personalizada, en Touriñán, J. M. (Dir.) Educación en valores, educación intercultural y formación para la convivencia pacífica. A Coruña: Netbiblo, 55-75.

Sáez Alonso, R. (2006). La educación intercultural como factor clave de la eficacia contra el racismo. Revista Española de Pedagogía, LXIV (234), 303-321.

Sales, R. (2010). What Is 'Britishness, and Is It Important?, en Calder, G., Cole, P. and Seglow, J. (eds.) Citizenship Acquisition and National Belonging. Migration, Membership and the Liberal Democratic State. New York: Palgrave Macmillan, 123-140.

Sen, A. (2007). Identidad y violencia. La ilusión del destino. Madrid: Katz.

Soriano, E. y Peñalva, A. (2011). Presente y futuro de la educación intercultural en la formación inicial de los profesionales de la educación. Aula Abierta, 39:1, 117-130.

Suárez Orozco, C. y Suárez Orozco, M. M. (2003). La infancia de la inmigración. Madrid: Morata.

Touriñán, J. M. (2006). La educación intercultural como ejercicio de educación en valores. ESE: Estudios sobre Educación, Junio, 10, 9-36.

Wulf, Ch. (2008). Antropología. Historia, cultura, filosofía. Barcelona: Anthropos. 


\section{PALABRAS CLAVE}

Competencia social, educación intercultural, asimilacionismo, inmigración, valores.

\section{KEY WORDS}

Social competence, intercultural education, assimilation, immigration, values.

\section{PERFIL ACADÉMICO Y PROFESIONAL DE LOS AUTORES}

José Antonio Ibáñez-Martín, Catedrático Emérito de la Universidad Complutense de Madrid. Líneas de investigación: bases antropológicas y supuestos crítico-filosóficos de los procesos educativos, finalidades educativas, política de la educación y legislación educativa con especial referencia a la dimensión europea, educación cívica y moral dentro de los sistemas democráticos, ética de la educación y deontología profesional de las actividades educativas. Sobre este conjunto de temas ha publicado más de cien trabajos en cinco lenguas diversas.

Juan Luis Fuentes, Diplomado en Educación Social y Licenciado en Pedagogía por la Universidad Complutense de Madrid con Premio Extraordinario de Licenciatura y Premio Nacional a la Excelencia en el Rendimiento Académico. Actualmente es becario FPU del Departamento de Teoría e Historia de la Educación de dicha universidad donde se encuentra realizando la tesis doctoral en torno a los fundamentos teóricos de la educación intercultural.

José María Barrio Maestre, Doctor en Filosofía con Premio Extraordinario. Amplió estudios en de Münster (Alemania). Profesor Titular en el departamento de Teoría e Historia de la Educación. Ha publicado 13 libros y más de 70 artículos en revistas sobre los temas de su investigación: Antropología Pedagógica, Ética de la Educación y Educación Cívica. Su último libro: La gran dictadura. (Madrid, 2010).

Dirección de los autores: Facultad de Educación

Universidad Complutense de Madrid

C/ Rector Royo Villanova s/n

28040. Madrid

E-mail: josibama@edu.ucm.es

juanluis.fuentes@edu.ucm.es

jmbarrio@edu.ucm.es 
Fecha Recepción del Artículo

Fecha Revisión del Artículo

Fecha Aceptación del Artículo

Fecha de Revisión para publicación
21. Enero. 2011

12. Mayo. 2011

22. Junio. 2011

01. Diciembre. 2011 